\title{
Behavioural and cognitive effects of simvastatin dose used in stimulation of bone regeneration in rats ${ }^{1}$
}

\author{
Dircilei Nascimento de Sousa ${ }^{\mathrm{I}}$, Washington Macedo de Santana ${ }^{\mathrm{II}}$, Vania Moraes Ferreira ${ }^{\mathrm{III}}$, Wagner Rodrigues Duarte ${ }^{\mathrm{IV}}$ \\ IFellow Master degree, Postgraduate Program in Health Sciences, Health Sciences Faculty, Brasília University (UNB), Brasília-DF, Brazil. Surgical \\ procedures, acquisition and interpretation of data, manuscript writing. \\ IIFellow PhD degree, Postgraduate Program in Health Sciences, Health Sciences Faculty, UNB, Brasília-DF, Brazil. Surgical procedures, acquisition \\ and interpretation of data, manuscript writing. \\ IIIPhD, Full Professor, Health Sciences Faculty, UNB, Brasília-DF, Brazil. Statistical analysis, English language, critical revision. \\ ${ }^{\text {IV }} \mathrm{PhD}$, Full Professor, Health Sciences Faculty, UNB, Brasília-DF, Brazil. Conception and design of the study, manuscript writing.
}

\begin{abstract}
PURPOSE: To analyze the effects of simvastatin (SVT) in the locomotion, anxiety and memory of rats, as a reflection of the administration of a minimum dose capable of stimulating bone regeneration in defects in the calvariae.

METHODS: Surgical procedures were performed in 15 female Wistar rats, 2-month old, to insert the grafting material regenerator (Bone-ceramic ${ }^{\circledR}$ ) and/or SVT, followed by behavioural and cognitive assessments in the $7^{\text {th }}, 30^{\text {th }}$ and $60^{\text {th }}$ days post surgery.

RESULTS: The SVT locally applied with the goal of bone regeneration in defects created in rat calvariae does not interfere with locomotion, anxiety levels and/or memories of rats, except for the first week following surgery, when an anxiolytic effect was observed, as a result of a possible central action.
\end{abstract}

CONCLUSION: Failure to provoke any response within 30 and 60 days post surgical procedures suggests that SVT may constitute a good choice in stimulating bone regeneration without affecting the long term neural functions.

Key words: Cognition. Behavior. Simvastatin. Bone Regeneration. Rats. 


\section{Introduction}

For many years the gold standard applied to bone grafting has been of the autogenous type. The bone graft is obtained from the same patient from different intra- or extra-oral donor regions, such as parts of the mandible, skullcap or tibia ${ }^{1}$. The search for a bone substitute has increased over the years due to the limited volume of bone removed from the donor area and mainly because of surgical morbidity ${ }^{2}$. The search for a material that eliminates the need to intervene in the donor area could lead to further advances in biomaterials research and the production of different bone substitutes.

There are some factors that are valuable in bone regeneration, e.g., hormones, cytokines and growth factors, such as bone morphogenetic protein ${ }^{3}$, drugs such as calcitonin ${ }^{4}$ and statins ${ }^{5}$. The latter, in turn, are widely used to lower blood cholesterol level and can stimulate bone formation, as observed by the increasing activity of the alkaline phosphatase, osteocalcin expression levels and mineral deposits, suggesting an anabolic effect on bone tissue by increasing osteoblast differentiation ${ }^{6}$. Some studies suggest that simvastatin (SVT) enhances differentiation of osteoblasts in humans, measured by increased alkaline phosphatase activity and the expression of osteoblast-related genes ${ }^{7}$.

Although there is a great deal of information indicating the beneficial effect of SVT in bone regeneration, results of preclinical and clinical studies have shown conflicting results with its use. Studies indicate that the effects of SVT may be influenced by factors such as method and route of administration and duration of exposure. In addition, there are also many questions about the optimal concentration and the best carrier for the drug. The materials available for bone regeneration are still expensive and unaffordable to many patients, and therefore, there is a tireless search by the scientific community for a biomaterial that is efficient and, at the same time, accessible to the majority of the population ${ }^{6,8}$.

Attention should also be given to the fact that the SVT influence another aspect that cannot be ruled out in this present context, which concerns to their interference on aspects of neurobehaviour. In recent years, attention has been given to this statin in the treatment of anxiety and depression ${ }^{9,10}$, for its therapeutic potential in the treatment of neurodegenerative diseases involving excitotoxicity ${ }^{11}$, and loss of learning and memory ${ }^{12}$. Nevertheless, to the best of our knowledge, no work in the literature has investigated whether a low dose of SVT, able to promote bone healing, may interfere with the cognitive and behavioural aspects of the users.
In order to investigate this, the aim of this study was to assess the behavioural and cognitive effects of the SVT dose seeking to stimulate bone regeneration in defects created in the calvariae of rats.

\section{Methods}

Research approved by the Ethics Committee on Animal Use, Faculty of Medicine, University of Brasília (protocol UnB doc 44299-2012).

Fifteen female 2-month old Wistar rats were used at the beginning of the experiments, each weighing $300 \mathrm{~g}$, originating from the Animal Facilities of the Faculty Sena Aires (Valparaiso de Goias, GO, Brazil). The animals were housed in groups of five per cage, kept under standard conditions with food and water ad libitum, room temperature, light/dark cycle of 12 hours (06:00 to $18: 00 \mathrm{~h}$ ), After the surgical procedures and the behavioural assessments, the animals were sacrificed by decapitation eight weeks after the onset of the experiments, which is the time required for bone healing in rats. The brains were dissected and stored in $10 \%$ formalin for further studies.

\section{Preparation of simvastatin}

The ideal amount of BoneCeramic ${ }^{\circledR}$ (BC) and SVT solution to fill a bone defect $5 \mathrm{~mm}$ in diameter was standardized, using a condensation silicone template created to mimic the bone defect. We determined that collagen sponge (CS) or 15 $\mathrm{mg}$ of $\mathrm{BC}$ and $15 \mu \mathrm{L}$ of a SVT $(\mathrm{BC}+\mathrm{SVT})$ solution in ethanol were sufficient to fill the designed defect. The SVT solution (Farmogral ${ }^{\circledR}$, Brasilia, Brazil) was prepared to contain $0.1 \mathrm{mg}$ of SVT in $15 \mu \mathrm{L}$ of SOLUTION ${ }^{23}$.

\section{Anaesthesia and surgery procedures}

The rats were anesthetized with ketamine $(80 \mathrm{mg} / \mathrm{kg})$ and xylazine $(10 \mathrm{mg} / \mathrm{kg})$ by intramuscular route before the induction of bilateral defects in the calvariae. The rat's skulls were desinfected with povidone-iodine solution, a linear incision was made on the region, and a full thickness flap elevated exposing the bone. A $5 \mathrm{~mm}$ diameter trephine Neodente ${ }^{\circledR}$ drill (Curitiba, PR, Brazil) was used to create a bone defect on both sides of the calvariae, totalling two bone defects on each rat. Constant irrigation with a saline solution was used in order to avoid overheating the bone. The defects were filled with different materials as described below. At the end of the surgical procedures, a suture was made using a mononylon 
5.0Etchon ${ }^{\circledR}$ thread, as demonstrated in Figure 1. During surgery procedures special care was taken not to damage the duramater. All surgical instruments had been sterilized in an autoclave. For pain management after surgery recovery and on the next day, 150 $\mathrm{mg} / \mathrm{kg}$ of acetylsalicylic acid was administered, by the gavage route every four hours.

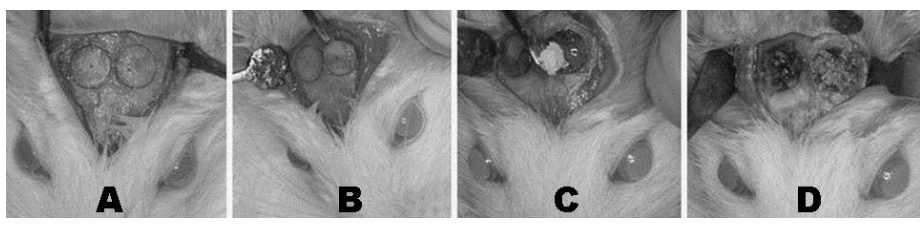

FIGURE 1 - Illustrations of the sequence of surgical procedures for the induction of bilateral defects in the calvariae of rats. A) Demarcation of the area where the bone defect is to be performed; B) Removal of the bone layer that characterizes the bone defect; C) Administration of a substance corresponding to what was chosen for each investigated group, D) area procedure finalized and ready to be sutured.

\section{Experimental design}

The animals were behaviourally assessed on the $7^{\text {th }}, 30^{\text {th }}$ and $60^{\text {th }}$ days after surgical procedures in order to verify the level of stress/anxiety and any cognition impairment. For the purposes of the experiments and control, the animals were divided into three groups of five animals each

Group 1 (G1): In this control group the bone defects was made on the left side to receive no treatment, being filled only with the blot clot. On the right side the bone defects received different types of fillers: $\mathrm{BC}, \mathrm{BC}+\mathrm{SVT}, \mathrm{CS}$, or $\mathrm{CS}+\mathrm{SVT}$.

Group 2 (G2): (100\% synthetic bone substitute, osteoconductive, made up of biphasic calcium phosphate particles) - on the left side the bone defects received treatment only with $\mathrm{BC}$, while the right side received $\mathrm{BC}+\mathrm{SVT}$.

Group 3 (G3): On the left side the bone defects received $\mathrm{CS}$, and on the right side the animals received CS+ SVT.

\section{Behavioural tests}

Animals were acclimated to the experimental room for at least $1 \mathrm{~h}$ before beginning the experimental procedures, which were carried out between 8 a.m. and 12 p.m. in order to avoid circadian influence and or any kind of noise or interference from external factors in the experimental environment. The behavioural tests were conducted with each separate group of animals $(n=5$ animals in each group), as demonstrated in Figure 2.

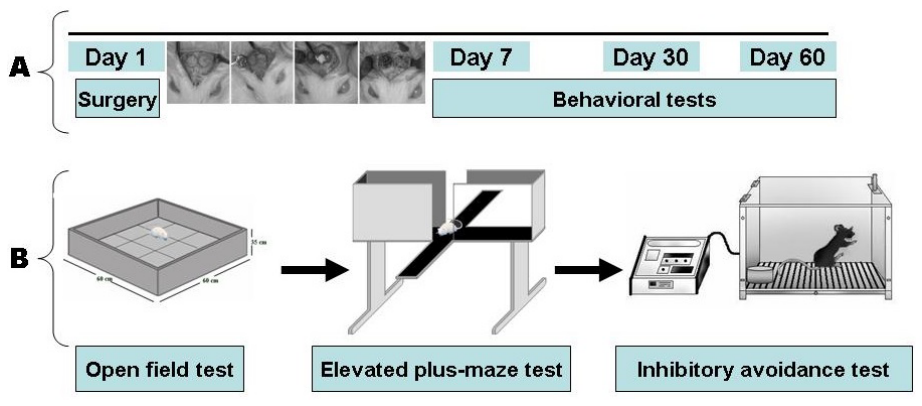

FIGURE 2 - Schematic representation of the steps of the experimental procedures adopted in the research. A) The surgeries took place on day 1 of the beginning of the experiments, and behavioural evaluations occurred on the $7^{\text {th }}, 30^{\text {th }}$ and $60^{\text {th }}$ days after anaesthesia and surgery procedures in order to verify the level of stress/anxiety and some cognition impairment; B) The tests used in the research were open field (locomotion); elevated plus-maze (anxiety); and "step down" inhibitory avoidance (memory) tests.

Open field test: The animals were individually placed in the centre of a wooden arena $\left(60 \times 60 \times 35 \mathrm{~cm}^{3}\right)$ divided into nine quadrants, to evaluate the number of sections crossed by the animal during $5 \mathrm{~min}$. Immediately after the animal was placed in the centre of the arena, its movements began to be scored. Locomotor activity was considered only when the animal placed all four paws onto one square.

Elevated plus maze test: This apparatus was used on the basis of its documented validity to detect both anxiolytic- and anxiogenic-like drug effects in rats ${ }^{13}$. Made of wood and covered with impermeable Formica, it was placed $50 \mathrm{~cm}$ above the floor. The four arms were $50 \mathrm{~cm}$ long and $10 \mathrm{~cm}$ wide. Two opposite arms were surrounded by walls (40 $\mathrm{cm}$ high, enclosed arms), while the other two were devoid of enclosing walls (open arms) surrounded by a 1 $\mathrm{cm}$ high Plexiglas edge. The four arms were connected by a central platform $\left(10 \times 10 \mathrm{~cm}^{2}\right)$. Each rat was placed in the centre of the maze facing an enclosed arm. The animals were observed for a 5-min test period and the anxiogenic-like effects were defined as a decrease in the proportion of open arm entries divided by the total number of arm entries, and a decrease in the time spent on open arms relative to the total time spent on both arms. Whenever a rat placed all four paws onto one arm, one entry was recorded. The total number of enclosed arm entries was also used as a measure of locomotor activity.

Inhibitory avoidance task: The equipment was an acrylic box ( $50 \mathrm{~cm} \times 25 \mathrm{~cm} \times 25 \mathrm{~cm}$ ), the floor of which consisted of parallel stainless steel bars (1 mm diameter) spaced $1 \mathrm{~cm}$ apart. A platform (7$\mathrm{cm}$ wide $\mathrm{x} 2.5-\mathrm{cm}$ high) was placed on the floor against the left wall. The animals were placed on the platform, and the time from latency to step-down on the grid with four paws was measured with an automatic device. The experimental subjects were submitted to the inhibitory avoidance task using a protocol similar to that previously described ${ }^{14}$. During training sessions, immediately after stepping down on the 
grid, the animals received a $0.4-\mathrm{mA}, 1.0$-s scrambled foot shock. During test sessions, no foot shock was administered, and the stepdown latency (maximum $180 \mathrm{sec}$ ) was used as measure of memory retention. Animals were submitted to a single training session. In order to evaluate short-(STM) and long-term (LTM) memories, test sessions were performed $1 \mathrm{~h}$ and $24 \mathrm{~h}$ after training, respectively.

\section{Statistical analysis}

The results were expressed as the mean \pm SEM (standard error of the mean) of 15 animals (five animals/group). Data were analyzed using a GraphPad Prism v5 statistical program. Locomotion and anxiety-related behaviour were analyzed using the one way Analysis of variance (ANOVA) followed post hoc by the Newman-Keuls test. Data on the inhibitory avoidance task are shown as the medians (interquartile range) of step-down latencies. Comparisons of the step-down test session latencies among groups were performed with using the Kruskal-Wallis test followed by Dunn's multiple comparison test. Statistical significance was considered when $\mathrm{p} \leq 0.05$.

\section{Results}

The evaluation of SVT administration in the calvariae of rats for locomotor activity on the $7^{\text {th }}, 30^{\text {th }}$ and $60^{\text {th }}$ post-surgical days is demonstrated in Figure 3. Statistical analysis performed by the one-way ANOVA did not detect any statistical difference among the groups and/or in the recovery time of the animals $\left[\mathrm{F}_{(2,14)}=2.022, \mathrm{p}=0.1750\right]$.

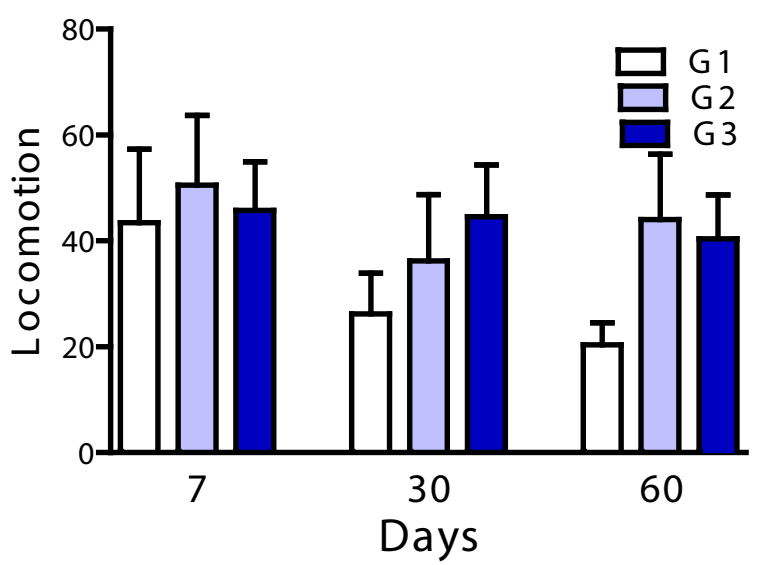

FIGURE 3 - Effects of simvastatin $(0.1 \mathrm{mg} / \mathrm{kg})$ on locomotor activity of rats evaluated in the open field test for $5 \mathrm{~min}$, on the $7^{\text {th }}, 30^{\text {th }}$ and $60^{\text {th }}$ days post surgery. The results are expressed as mean \pm SEM of five animals per group. G1 = control group; G2= left side: BoneCeramic $^{\circledR}(\mathrm{BC}) /$ right side: BoneCeramic $^{\circledR}+$ simvastatin $(\mathrm{BC}+\mathrm{SVT}) ; \mathbf{G} 3=$ left side: Collagen sponge (CS)/right side: Collagen sponge + simvastatin $(\mathrm{CS}+\mathrm{SVT})$.
To evaluate the anxiety levels, the animals were tested in the EPM (Figure 4), which the percentage of entries into the open arms of the maze and the time spent in these arms were considered. The one-way ANOVA followed by a post hoc Newman Keuls test detected an increase in the percentage of open arm time of the EPM on the $7^{\text {th }}$ day post surgery $\left[\mathrm{F}_{(2,14)}=8.209, \mathrm{p}=0.0057\right]$, but not in any other of the assessments. This behaviour response seemed to be specific to an anxiolytic effect of SVT expected early after treatment, although the frequency of enclosed arms entries of the $\operatorname{EPM}\left[\mathrm{F}_{(2,14)}=0.5566, \mathrm{p}=0.5873\right]$ was not affected.
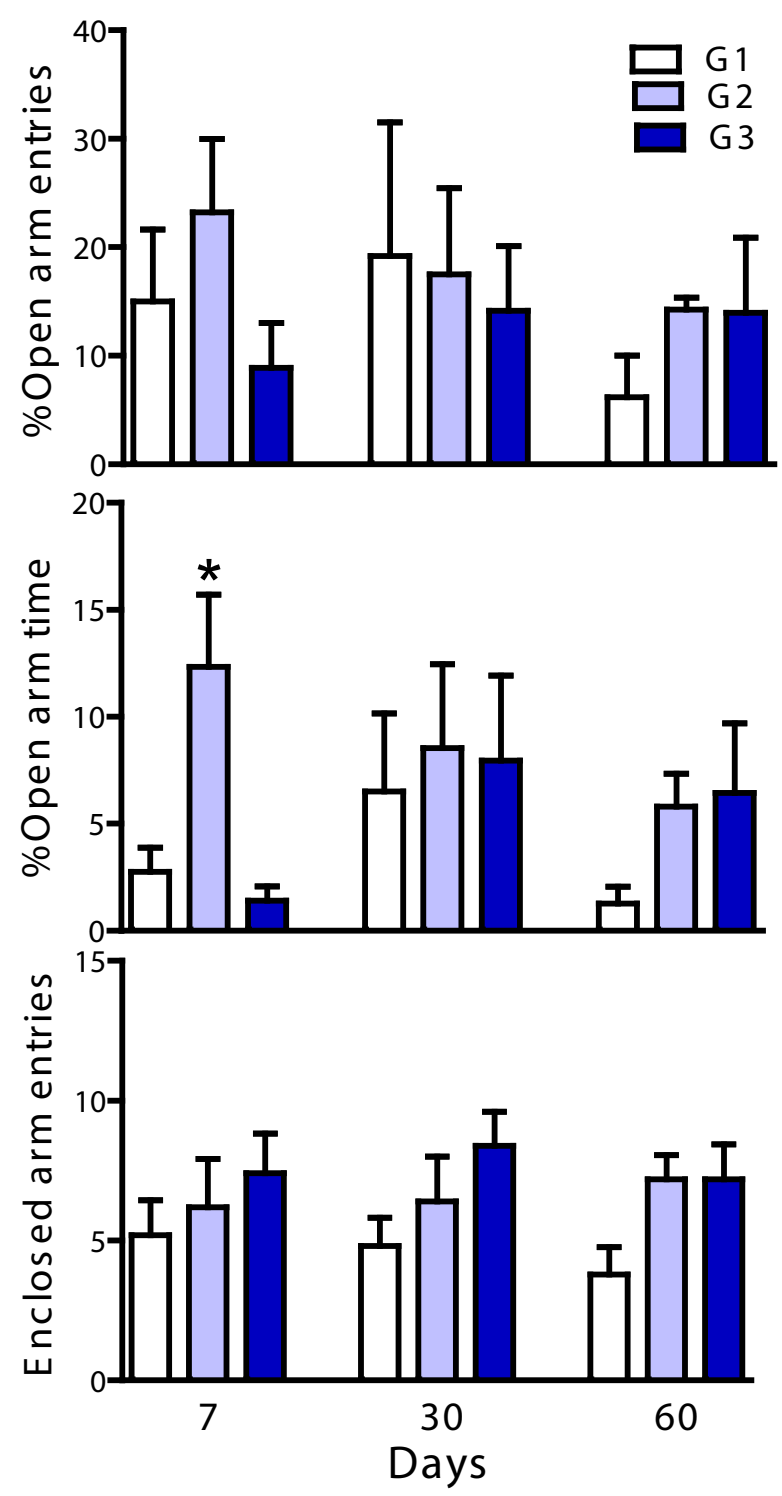

FIGURE 4 - Effects of simvastatin $(0.1 \mathrm{mg} / \mathrm{kg})$ on the anxiety-like behaviour of rats evaluated in the elevated plus maze test on the $7^{\text {th }}, 30^{\text {th }}$ and $60^{\text {th }}$ days post surgery. The results are expressed as mean \pm SEM of five animals per group. ${ }^{*} \mathrm{p} \leq 0.05$ compared to the control group $(\mathrm{G} 1)$ on the $7^{\text {th }}$ day post surgery (One way ANOVA; Newman-Keuls test). G1= control group; G2 = left side: BoneCeramic ${ }^{\circledR}(\mathrm{BC}) /$ right side: BoneCeramic ${ }^{\circledR}+$ simvastatin $(\mathrm{BC}+\mathrm{SVT}) ; \mathbf{G 3}=$ left side: Collagen sponge $(\mathrm{CS}) /$ right side: Collagen sponge + simvastatin $(\mathrm{CS}+\mathrm{SVT})$. 
The STM and LTM were investigated in the step down inhibitory avoidance test, by which the animals had to recognize the aversive stimulus when they were evaluated 1 hour (STM) or 24 hours (LTM) after training on the $7^{\text {th }}$ day post surgery, and then again on the $30^{\text {th }}$ and $60^{\text {th }}$ days (Figure 5). The animals recognized the stimulus and increased their latency time on the platform of the apparatus, for STM on the $7^{\text {th }}$ day [11.62, $\left.\mathrm{p}=0.02\right]$ and the $30^{\text {th }}$ day [13.02, $\mathrm{p}=0.01]$. LTM also made a difference compared to the control group on the $60^{\text {th }}$ day [11.41, $\left.\mathrm{p}=0.02\right]$. No statistical difference was observed between STM and LTM or LTM over time in each group.

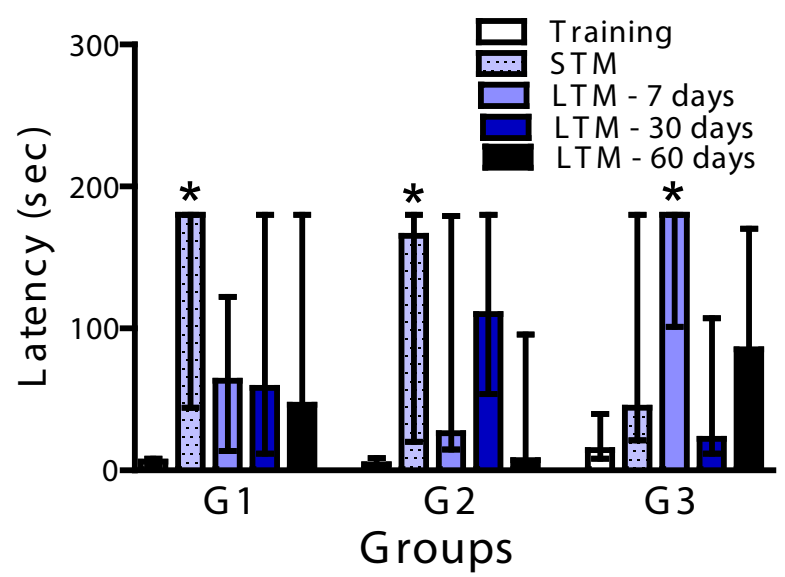

FIGURE 5 - Effects of simvastatin $(0.1 \mathrm{mg} / \mathrm{kg})$ on short- and long-term memories of rats evaluated in the "step-down" inhibitory avoidance test on the $7^{\text {th }}, 30^{\text {th }}$ and $60^{\text {th }}$ days post surgery. The results are expressed as mean \pm SEM of 5 animals per group. STM was evaluated $1 \mathrm{~h}$ after the training. LTM was evaluated $24 \mathrm{~h}$ after STM on the $7^{\text {th }}$ day post surgery, and again on the $30^{\text {th }}$ and $60^{\text {th }}$ days. ${ }^{*} \mathrm{p} \leq 0.05$ compared to the control group (G1) on $7^{\text {th }}$ day post surgery (Kruskal-Wallis test, followed by Dunn's multiple comparison). G1 = control group; G2= left side: BoneCeramic ${ }^{\mathbb{B}}(\mathrm{BC}) /$ right

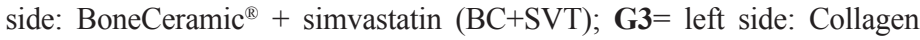
sponge $(\mathrm{CS})$ / right side: Collagen sponge $+\operatorname{simvastatin}(\mathrm{CS}+\mathrm{SVT})$.

\section{Discussion}

In a general context, the results showed that the SVT doseseeking bone regeneration in defects created in rat calvariae, does not interfere with behavioural and/or cognitive responses, except after the first week after application, which showed an anxiolytic effect, reflecting a possible action arising from the first specific effects of the SVT on the central nervous system. On the other hand, the lack of response on the $30^{\text {th }}$ and $60^{\text {th }}$ days corresponding to the period of surgical recovery suggests that SVT may be a good choice in stimulating bone regeneration without affecting longterm locomotion, anxiety levels and aspects of memory.
It is well known that the natural behaviour of rodents (rats and mice) can be measured by the number of enclosed arm entries into a maze and by locomotor activity in an open field test. Researchers have noted that rodents are motivated to investigate new objects and places, but the novelty also induces fear, which may tend to suppress exploration or encourage them to flee from the new situation $^{15}$. Drugs (or other manipulations) that reduce the presumed inhibitory mechanism can increase the levels of exploitation, without affecting the responses to novelty ${ }^{16}$. The results obtained in the present study showed that SVT did not interfere with locomotion, since the locomotion of the animals remained independent of the treatment and the period of time investigated

Regarding anxiety, this behaviour, very common in everyday life, is also present in the dentist's chair, independent of the clinical manifestations presented by patients. There is a good reason to believe that the same neural systems are involved in the generation of the phenomena of acute physiological states of fear and anxiety, even though the situations and conditions that lead to physiological and pathological anxiety are different ${ }^{17}$. Anxiety disorders that are more directly related to phobic situations or originating from phobic stimuli are classified as exogenous anxiety. Furthermore, there are multiple types of anxiety disorders, each one with a characteristic pattern of response. Major advances have been made towards understanding the neurobiology of fear responses ${ }^{18}$.

Several studies have suggested the influence of SVT as a probable therapy for treating anxiety and other changes related to this disorder ${ }^{9,10,19}$. Based on this information, our interest was to know how far a low dose intended for use in bone regeneration could also interfere with behaviour. It was observed on the $7^{\text {th }}$ day post surgery that the animals showed a significant anxiolytic response, depending on the osteoconductive material used. An adaptation of the response to the latter was demonstrated, whereas no similar behaviour or other kind of behaviour alteration was observed during the recovery of the animals in the process of bone regeneration.

With respect to the correlation between locomotor activity and anxiety-related behaviour, our results were the opposite of those produced by the previous reports on SVT hyperactivity in the animals; this was a reflection of the high amount of exploration time of the animals in the open arm of EPM, suggestive of anxiolytic effect ${ }^{19}$. Locomotion of the animals used in our research did not alter during the tests. These conflicting results may be are due to the dose used. Authors used a very high dose of $10 \mathrm{mg} / \mathrm{kg} /$ day, whereas in our studies the dosage was $0.1 \mathrm{mg} / \mathrm{kg}$, which was enough to produce bone regeneration (data not shown) without significant interference in behaviours investigated after the first week of surgical recovery. 
Attention is drawn here to the fact that in the first week of surgery recovery, the animals showed anxiolytic effect that was osteoconductive- dependent. There are no reports in the literature emphasizing the anxiolytic property of BoneCeramic ${ }^{\mathbb{B}}$ and any mechanism by which it might induce such behaviour. However, it is well known that pre-clinical studies have shown that the major receptor involved in the observed responses is the N-methyl-D-aspartate (NMDA) receptor. In some of the research previously reported, SVT behaved as an antagonist of these receptors ${ }^{19}$. Considering this hypothesis, it is possible to justify the fact that the anxiolytic response observed in animals undergoing surgical procedures may perhaps have involved the NMDA receptors.

In addition, emphasis also has been given to the fact that statins have shown neuroprotective effects in some neurological diseases. In a comparative study on the effect of commercially available statins on the neural damage and memory impairment in mice produced by Kainate, which is a glutamate agonist, SVT was more effective in reducing the harmful effects, including the severity of seizures, excitotoxicity, oxidative damage, neuritic and apoptosis dystrophy ${ }^{11}$. With the SVT dose used in the present experiment, the animals showed no significant changing in STM and LTM, regardless of the time of bone regeneration.

The mechanism by which SVT promotes bone regeneration has long been investigated, showing that the influence of lipid-lowering therapies generates many positive results. On the other hand, there are many contradictory results with regard to the role of cholesterol in cognitive functions. However, it is clear that the conflicting data are mainly due to changes in dosage and duration of treatment in subjects investigated. For example, the effect of local application of SVT on bone growth is more favourable with lower doses $(2.2 \mathrm{mg}$ to $0.5 \mathrm{mg}$ ), reducing inflammation to clinically acceptable levels ${ }^{8}$. The optimal dose to stimulate maximum bone regeneration without inducing inflammation in rat calvariae is $0.1 \mathrm{mg}$, especially if associated with an osteoconductive biomaterial able to release the drug gradually ${ }^{20}$. Our results support this information. SVT in a dose of $0.1 \mathrm{mg}$ is effective in regenerating bone in rat calvariae with no considerable effect at central nervous system.

In overall, the results here obtained with the SVT dose administered locally in rat calvariae may constitute an alternative to bone regeneration without substantial central interference over time. Furthermore, attention should be given to the fact that local osteogenesis helps to accelerate bone regeneration making SVT a valuable investment for the pharmaceutical industry in search of the advances in this regard.

\section{Conclusion}

Failure to provoke any response within 30 and 60 days post surgical procedures suggests that SVT may constitute a good choice in stimulating bone regeneration without affecting the long term neural functions

\section{References}

1. Veis A, Tsirlis T, Parisis NA. Effect of autogenous harvest site location on the outcome of ridge augmentation for implant dehiscences. Int J Periodontics Restorative Dent. 2004;24:155-63.

2. Jensen SS, Broggini N, Hjrting-Hansen E,Schenk R, Buser D. Bone Healing and graft resorption of autograft, anorganic bovine bone and $\beta$-tricalcium phosphate. A histologic and histomorphometric study in mandibles of minipigs. Clin Oral Implants Res 2006;17:237-43.

3. Nyan M, Hao J, Miyahara T, Noritake K, Rodriguez R, Kasugai S. Accelerated and enhanced bone formation on novel simvastatinloaded porous titanium oxide surfaces. Clin Implant Dent Relat Res. 2013 [Epub ahead of print].

4. Ma L, Xiang L, Yao Y, Yuan Q, Li L, Gong P. CGRP-alpha application: a potential treatment to improve osseoperception of endosseous dental implants. Med Hypotheses. 2013;81:297-9.

5. Liu X, Li X, Zhou L, Li S, Sun J, Wang Z, Gao Y, Jiang Y, Lu H, Wang Q, Dai J. Effects of simvastatin-loaded polymeric micelles on human osteoblast-like MG-63 cells. Colloids Surf B Biointerfaces. 2013;102:420-7.

6. Baek KH, Young Lee W, Oh KW, Tae HJ, Lee JM, Lee EJ, Han JH, Kang MI, Cha BY, Lee KW, Young Son H, Kang SK. The effect of simvastatin on the proliferation and differentiation of human bone marrow stromal cells. J Korean Med Sci. 2005;20:438-44.

7. Maeda T, Matsunuma A, Kawane T, Horiuchi N. Simvastatin promotes osteoblast differentiation and mineralization in MC3T3-E1 cells. Biochem Biophys Res Commun. 2001;280:874-7.

8. Stein D, Lee Y, Schmidt MJ, Killpack B, Genrich MA, Narayana N, Marx DB, Cullen DM, Reinhardt RA. Local simvastatin effects on mandibular bone growth and inflammation. J Periodontol. 2005;76:1861-70.

9. Kilic FS, Ozatik Y, Kaygisiz B, Baydemir C, Erol K. Acute antidepressant and anxiolytic effects of simvastatin and its mechanisms in rats. Neurosciences (Riyadh). 2012;17:39-43.

10. Santos T, Baungratz MM, Haskel SP, de Lima DD, da Cruz JN, Magro DD, da Cruz JG. Behavioral interactions of simvastatin and fluoxetine in tests of anxiety and depression. Neuropsychiatr Dis Treat. 2012;8:413-22.

11. Ramirez C, Tercero I, Pineda A, Burgos JS. Simvastatin is the statin that most efficiently protects against kainate-induced excitotoxicity and memory impairment. J Alzheimers Dis. 2011;24:161-74.

12. Chauhan NB, Gatto R. Restoration of cognitive deficits after statin feeding in TBI. Restor Neurol Neurosci. 2011;29:23-34.

13. Pellow S, Chopin P, File SE, Briley M. Validation of open: closed arm entries in an elevated plus-maze as a measure of anxiety in the rat. J Neurosci Methods 1985;14:149-67.

14. Lucena GM, Prediger RD, Silva MV, Santos SN, Silva JF, Santos AR, Azevedo MS, Ferreira VM. Ethanolic extract from bulbs of Cipura paludosa reduced long-lasting learning and memory deficits induced by prenatal methylmercury exposure in rats. Dev Cogn Neurosci. 2013;3:1-10.

15. Montgomery KC. The relation between fear induced by novel stimulation and exploratory behaviour. J Comp Physiol Psychol. $1955 ; 48: 254-60$ 
16. Gray JA. Drug effects on fear and frustration: possible limbic site of action of minor tranquilizers. Handbook of psychopharmacology 8 (1977): 433-529.

17. Haefely W. Benzodiazepine receptor and ligands: structural and functional differences. Bezodiazepines: current concepts: biological, clinical and social perspectives. Wiley, Chicester; 1990. p.1-18.

18. Carlsson SG, Wide Boman U, Lundgren J, Hakeberg M. Dental anxiety - a joint interest for dentists and psychologists. Eur J Oral Sci. 2013;121:221-4.

19. Wang Q, Zengin A, Deng C, Li Y, Newell KA, Yang GY, Lu Y, Wilder-Smith EP, Zhao H, Huang XF. High dose of simvastatin induces hyperlocomotive and anxiolytic-like activities: the association with the up-regulation of NMDA receptor binding in the rat brain. Exp Neurol. 2009;216:132-8.

20. Nyan M, Sato D, Kihara H, Machida T, Ohya K, Kasugai S. Effects of the combination with alpha-tricalcium phosphate and simvastatin on bone regeneration. Clin Oral Implants Res. 2009;20:280-7.

\section{Correspondence:}

Dircilei Nascimento de Sousa

Universidade de Brasília

Faculdade de Ciências da Saúde

Programa de Pós-Graduação de Ciências da Saúde

Campus Universitário Darcy Ribeiro, s/n

70.910-900 Brasília-DF Brasil

Tel.: (55 61)9984-0106

dircileinascimento@hotmail.com

Received: Nov 14, 2013

Review: Jan 15, 2014

Accepted: Feb 18, 2014

Conflict of interest: none

Financial source: none

${ }^{1}$ Research performed at Pathology Laboratory, School of Medicine, Brasilia University (UNB), Brasilia-DF, Brazil. Part of Master degree thesis, Postgraduate Program in Health Sciences, Health Sciences Faculty, UnB. Tutor: Dr. Wagner Rodrigues Duarte. 